\title{
Pain 'memories' in phantom limbs: review and clinical observations
}

\author{
Joel Katz ${ }^{\text {a.b }}$ and Ronald Melzack ${ }^{a}$
}

\begin{abstract}
Summary This paper reviews reports of phantom limb sensations which resemble somatosensory events experienced in the limb before amputation. It also presents descriptions of this phenomenon in 68 amputees who took part in a series of clinical studies. These somatosensory memories are predominantly replicas of distressing pre-amputation lesions and pains which were experienced at or near the time of amputation, and are described as having the same qualities of sensation as the pre-amputation pain. The patients who experience these pains emphasize that they are suffering real pain which they can describe in vivid detail, and insist that the experience is not merely a cognitive recollection of an earlier pain. Reports of somatosensory memories are less common when there has been a discontinuity, or a pain-free interval, between the experience of pain and amputation. Among the somatosensory memories reported are cutaneous lesions, deep tissue injuries, bone and joint pain and painful pre-amputation postures. The experience of somatosensory memories does not appear to be related to the duration of pre-amputation pain, time since amputation, age, gender, prosthetic use, level of amputation, number of limbs amputated, or whether the amputation followed an accident or illness. The results suggest that somatosensory inputs of sufficient intensity and duration can produce lasting changes in central neural structures which combine with cognitive-evaluative memories of the pre-amputation pain to give rise to the unified experience of a past pain referred to the phantom limb. Implications for pre- and post-operative pain control are discussed.
\end{abstract}

Key words: Phantom limb pain; Somatosensory memory; Plasticity

\section{Introduction}

Many patients awake from the anesthetic after an amputation feeling certain that the operation has not been performed. They feel the lost limb so vividly that only when they reach out to touch it do they realize it has been cut off. This startling realization does nothing to diminish the reality of the limb they experience. Weir Mitchell [63] coined the term "phantom limb" to describe the phenom- enon and provided the first detailed study of painful and non-painful phantom limbs.

The phantom limb is usually described as having a tingling feeling and a definite shape that resembles the real limb before amputation [85]. It is reported to move through space in much the same way as the normal limb would move when the person walks, sits down, or stretches out on a bed. At first the phantom limb feels perfectly normal in size and shape - so much so that the amputee may reach for objects with the phantom hand, or try to step onto the floor with the phantom foot. As time passes, however, the phantom limb begins to change shape. The arm or leg becomes less distinct and may fade away al- 
together, so that the phantom hand or foot seems to be hanging in mid-air. Sometimes, the limb is slowly "telescoped" into the stump until only the hand or foot remains protruding from the stump tip [38]. In some cases, the phantom may also "shrink" in size so that the telescoped hand or foot fits snugly into the stump [20].

Pain is among the many sensations which define the phantom limb. The proportion of amputees with phantom limb pain is astonishingly high. Jensen and his colleagues [44,45], in a long-term investigation, found that $72 \%$ of amputees had phantom limb pain 8 days after amputation and $65 \%$ had it 6 months later. Two years later, phantom limb pain was reported by about $60 \%$. Fortunately, with time, the painful attacks decrease in frequency and intensity, for recent statistics indicate that in the long run only $7 \%$ of patients are helped by the more than 50 types of therapy used to treat phantom limb pain [81]. This low success rate reflects the extent of our ignorance about the mechanisms that underlie phantom limb pain.

One of the most striking properties of phantom limb pain is the persistence of pre-amputation pain in a proportion of amputees [60]. These patients may report that a pain experienced in a limb before amputation continues to be felt in the phantom after removal of the painful extremity. This type of phantom limb pain, characterized by the persistence or recurrence of a previous pain. is experienced with the same qualities and in the same area of the phantom limb as the pre-amputation pain. These somatosensory memorics are frequently felt so vividly that the amputee finds it difficult to believe that the limb has been removed.

Leriche [54.55] describes a patient who developed painful ulcerations of the Achilles tendon and surrounding region from an ill-fitting plaster cast. The ulcers had healed completely at the time of an unrelated amputation several months later. Although the patient subsequently developed stump pain. she did not suffer from pain in the phantom limb until 6 years later. when an injection into the stump instantly, and permanently, revived the pain of the ulcerated Achilles tendon. Nathan [67-69] reports a similar phenomenon after applying noxious stimuli to the stump of an amputee who later re-experienced the parn of ath ice-skate injury that he had sustained 5 years earlier when his leg was intact.

These fascinating phenomena have been described by a large number of clinical observer: and investigators during the past century. but have not received a critical review. This paper has 2 aims: (1) to examine and evaluate the earlier literature on somatosensory memories in phantom limbs, and (2) to document the phenomenon in detail in a group of 68 amputees.

\section{Review of the literature *}

Somatosensory memories are most frequently reported in patients whose lesions are associated with a loss of afferent input such as amputation. brachial plexus avulsion, spinal cord injury and spinal anesthesia [but see $25,54,70$ ]. It is not clear that deafferentation is necessary for somatosensory memories to occur, but when a missing or completely anesthetic limb continues to be the source of pain which resembles an old injury, one of the obvious conclusions is that the pain is centrally represented. This conclusion would not be obvious if the painful limb were present and fully functional.

The somatosensory memories in patients who have undergone deafferentation but still have the real limb are similar to those in amputees. Patients with brachial plexus avulsions $[46,66.76]$, spinal cord injuries $[6.10,18,26,34,37]$ and those undergoing spinal anesthesia $[93,98]$ sometimes report that the phantom limb is in the same uncomfortable. frequently painful, posture the real limb was in at the time of the accident or anesthetic block even when the patient can see that the paralyzed and insensitive real limb does not coincide with the felt position of the phantom limb [18]. Nathan [68] reports a patient in whom the pain of a fractured

\footnotetext{
* An annotated bibliography of the literature on somatosensory memories reviewed in this paper is available upon request from the authors. Also available is a table containing detailed information on the pains reported by the 68 amputees in the present study.
} 
patella, which had been excised 6 years earlier, was re-experienced shortly after bilateral cordotomy, and another, who continued to feel the pain of an ingrowing toe-nail after a complete spinal cord break.

There is also a literature on the persistence of painful and non-painful sensations associated with the removal or deafferentation of body structures other than the limbs, including breasts [13], teeth $[40,58,75,77]$ and internal and special sense organs. Ulcer pain has been reported to persist after vagotomy [92] or subtotal gastrectomy with removal of the ulcer [32], labor pain and menstrual cramps following total hysterectomy [23], the sharp, burning pain of cystitis despite complete removal of the bladder [12], and the pain of a severely ulcerated cornea after enucleation of an eye [62]. Some patients report the sensation of a full bladder and a feeling that they are urinating even though the bladder has been completely removed $[2,47]$. Sensations of passing gas and feces continue to be felt after the rectum has been removed $[19,28]$. These phantom sensations and pains are experienced as if the actual organs were still present. They are as real to the patient as were the original sensations which accompanied the normal functioning of the organs prior to their removal.

Clinical studies and case reports of somatosensory memories in phantom limbs of amputees can be divided into 2 classes based on whether the information provided is qualitative or quantitative. Case reports are generally rich in qualitative and descriptive details, but provide little information concerning the frequency with which somatosensory memories occur after amputation. On the other hand, studies involving larger numbers of amputees occasionally provide these statistics but with few descriptions, so that it is not known whether somatosensory memories are more likely to occur with some kinds of pains than with others. Table I contains a classification of the

TABLE I

SUMMARY TABLE OF LITERATURE REPORTING SOMATOSENSORY MEMORIES (SMs) EXPERIENCED AFTER LIMB AMPUTATION

References are classified according to the extremity amputated, temporal relation of the pre-amputation sensation to amputation, duration and intensity of the pre-amputation experience, and the time between amputation and the report of the SM. Table entries correspond to the reference source followed, in parentheses, by the number of patients/subjects reporting somatosensory memories.

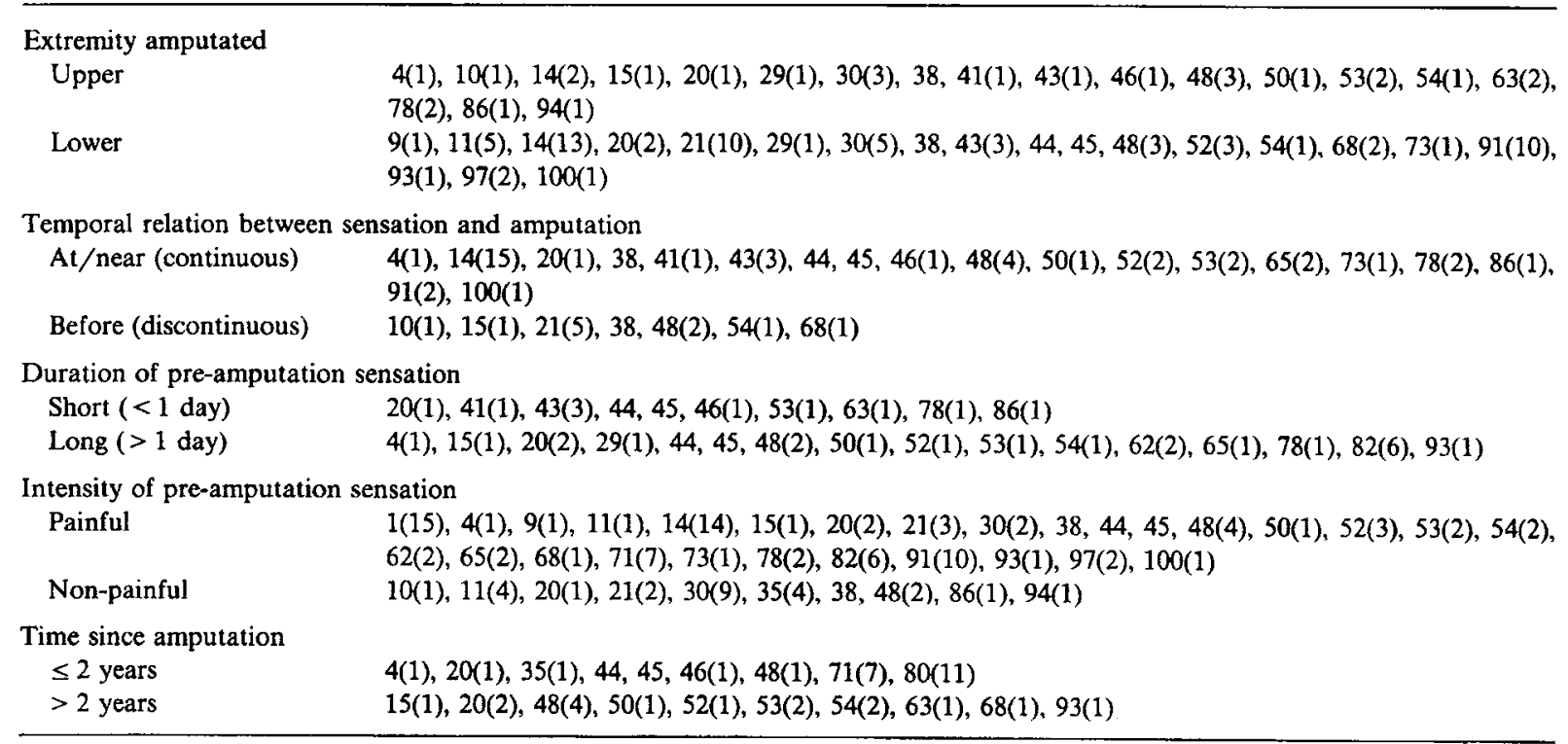


literature on somatosensory memories after limb amputation according to several variables, some of which appear to be important in establishing a central pain trace.

Case studies of amputees include somatosensory memories of cutaneous lesions such as painful diabetic and decubitus ulcers $[10,21,48,54$, $55,100]$, gangrene $[48,52,62,91]$, corns $[8,21,38,73]$, blisters [43], ingrown toe-nails $[38,43,73]$ and cuts or gashes $[50,53,63,67-69]$. Reports of deep tissue injuries [67-69] and pain from damage to bony structures $[20,67-69]$ which resemble pre-amputation experiences have also been represented in the phantom limb. The phantom may assume the same painful posture as that of the real limb prior to amputation, especially if the arm or leg has been immobilized for a long time $[9,14,29,41,48,63,78]$.

Most somatosensory memories correspond to painful pre-amputation experiences, but non-painful. "super-added" phantom sensations also occur. Super-added phantom sensations include the experience of a finger ring $[9,15,30,35,36,38,94]$, wristwatch and strap $[9,30,35,36,94]$, shoe [30,38], plaster cast $[21,87]$ and the handle of a cane which was being held when the hand was accidently amputated [86]. More complex somatosensory memories include the sensation of blood-filled boots [68] and blood trickling down the phantom limb $[11,38]$.

Despite these detailed descriptions, there is litthe information on the frequency with which somatosensory memories of different types of pain and sensation occur in the general population of amputees. Global statistics are occasionally provided in studies of groups of amputees but descriptive details are scant. For example, Browder and Gallagher's [14] figures indicate that 12 of 26 patients (46\%) with severe pain before the extremity was removed reported that the subsequent phantom limb pain bore a distinct resemblance to the pre-operative pain, but no qualitative information is provided. Similarly, Appenzeller and Bicknell [1] found that phantom limb pain was similar to the pain experienced before amputation in $79 \%$ of patients. Parkes [71] reported that about 50\% of his patients who had moderate or severe phantom limb pain said it resembled the pain they had experienced before amputation. Roth and Sugar- baker [80] reported that $17.5 \%$ of their amputees had phantom pains or sensations that mimicked pre-amputation experiences.

Sherman and his co-workers [82-84] surveyed American war veterans who sustained amputations related to military service, and civilian amputees whose amputations were primarily accident- and disease-related. In their earlier study [82] $37.5 \%$ of patients reported phantom limb pain of the same description and in the same location as the pre-amputation pain. In the other studies $[83,84]$ pain in the limb prior to amputation was not related to the subsequent development of phantom limb pain, but few details were given. Wall, Novotny-Joseph and Macnamara [97] found little support for a relationship between pre-amputation and phantom limb pain in their retrospective study of 25 patients who underwent hemipelvectomies or hip disarticulations for cancer of the lower extremities. Fourteen of the 16 patients who had had pre-amputation pain subsequently developed phantom limb pain as did 8 of the 9 who did not have any pre-amputation pain. Only 2 patients $(12.5 \%)$ reported that their phantom limb pain was identical in location to the pain they experienced prior to the amputation. A re-examination of the clinical records of the chronic pain patients studied by Katz and Melzack [48] reveals that 6 of the 8 amputees (75\%) reported having at least one type of phantom limb pain that was similar to the pain they had experienced before amputation.

Jensen et al. $[44,45]$ conducted the only prospective, long-term study designed to examine the relationship between pre-amputation pain and the subsequent development and course of phantom limb pain in a series of 58 amputees. Information was obtained regarding the general location and sensory character of pain experienced the day before amputation and again with respect to phantom limb pain, on 3 occasions after amputation. Eight days after amputation $74 \%$ of patients reported the location of the phantom limb pain to be similar to that of the pre-amputation pain. Two years later, almost half (45\%) still showed a similar location. The character of the phantom limb pain was similar in $53 \%$ and $35 \%$ of patients at the 8 day and 2 year interviews. respectively. When 
both location and quality were examined, $36 \%$ of patients showed a similarity 8 days after amputation and $10 \%$ showed it at the 6 month and 2 year follow-ups. However, the authors obtained only 3 general locations of the pre-amputation pain (entire limb, proximal and distal, distal) and provided only 14 descriptors (the McGill Pain Questionnaire contains 78 ) which precluded the kind of descriptions of meaningful somatic entities or events such as a painful blister on the heel, tight finger rings, a misshapen limb, a gash on the shin from an ice-skate blade and so forth.

To summarize, studies of groups of amputees report the incidence or prevalence of somatosensory memories after amputation but give little information about the types of pain which recur. Case reports present these descriptive details but without information regarding the frequency of their occurrence. These studies indicate that between $12.5 \%$ and $79 \%$ of amputees report similar pains before and after amputation. The wide range in estimates may be due to a variety of factors, including the criteria used to determine similarity, the type, severity and duration of the pre-amputation pain, temporal relation between the pain and amputation, time since amputation and whether a description of the pain was also obtained prior to amputation. But since many studies do not report information of this nature, it is not known which factors are most important. What is lacking is a systematic description and categorization of various types of pre-amputation pain which persist or recur following amputation, and an estimate of their relative frequencies of occurrence.

\section{A study of somatosensory memories in phantom limbs}

The review of the literature presented above reveals that somatosensory pain memories are a common occurrence after amputation, but more information is needed on how frequently they are reported to occur and whether the duration, location and type of pre-amputation pain is important in producing a pain "memory." The purpose of this study is to determine the frequency with which different types of pre-amputation pain are re- ported to be experienced as phantom pains after amputation.

\section{Methods}

Sample

Sixty-eight amputees (45 male, 23 female), ranging in age from 23-79 years (mean 58.7 years) volunteered to participate. There were 57 unilateral (including one with toes amputated on the contralateral limb as well), 1 ipsilateral double and 10 bilateral amputees for a total of $80 \mathrm{ampu}$ tations. The major reason for amputation was peripheral vascular disease (PVD) in 43 subjects (53 limbs) 23 of whom (27 limbs) also had diabetes mellitus (DM). The next most frequent cause of amputation was accident, which accounted for 12 subjects ( 13 limbs), followed by tumor in 5, arterial thrombosis in 3 , radiation damage in 2 , electrical burns in 1 ( 2 limbs), osteomyelitis in 1 and polio in 1 . The mean number of years since amputation was 4.9 (range 20 days to 46 years). Subjects were recruited from advertisements placed in local newspapers and newsletters, postings at orthopedic appliance shops, and hospitals serving the Montreal area. All potential subjects were informed that the study was investigating both painful and non-painful phantom limbs. At no time in the recruitment process was the relationship between pre- and post-operative pain mentioned. Informed consent to participate was obtained from all subjects.

\section{Procedure}

Subjects were interviewed as part of a larger project studying painful and non-painful phantom limbs. One portion of the interview examined the relationship between pain experienced in the limb before amputation and the subsequent development of phantom limb pain. Subjects were asked whether or not they had experienced pain in the limb before it was amputated. They were asked to describe, in their own words, the type of pain and its duration. Subjects with phantom limb pain were asked whether it was similar in quality, location, or intensity to the pain they experienced prior to the amputation (i.e., within a day of amputation). The term somatosensory memory of $a$ 
prior pain (SMp) will be used when referring to this type of phantom phenomenon. Subjects also were asked whether the phantom limb pain was similar to any other pain or lesion they may formerly have had. but was no longer present or had healed before the amputation was performed. The term somatosensory memory of a former pain (SMf) will be used when referring to this type of phantom phenomenon.

The difference between the 2 types of somatosensory memory is one of perceived continuity: SMps are described as the persistence of the preamputation pain and resemble sensations (and/or pains) that were present in the limb up to the time of amputation. Subjects with SMps often report that when first recovering from the anesthesia they believed that the amputation had not been done because they continued to feel their painful limb as it was prior to the anesthesia. SMfs are defined by a discontinuity or a pain-free interval between the time the pain (or sensation) was last experienced and the amputation.

\section{Inclusion criteria for somatosensory memories}

Retrospective reports such as these pose problems regarding their reliability and verifiability. These problems include (1) the reliance on the subject's memory to determine the relationship between the pre-amputation pain and phantom limb pain without an independent source of verification, (2) the possibility that some subjects with phantom limb pain will try to explain the pain by comparing it to a past pain, and (3) perceived demand characteristics to respond to the investigator's questions in a certain way.

The following procedures were implemented to minimize the influence of these 3 factors. Reports from subjects who were vague or appeared not to remember but "thought" that there was a similarity were excluded. Only subjects who claimed they were certain that the phantom pain was the same as. or very similar to, the pre-amputation pain were questioned further. After this initial indication that a similarity existed, 2 conditions had to be met in order for phantom phenomena to qualify as somatosensory memories. The subjects had to indicate that (a) the quality and (b) the location of the pre-amputation and phantom sensations were the same. This was readily established for pain associated with a pre-amputation lesion which had a visual component, for these were frequently described in one statement (e.g. "I can feel my. ingrown toe-nail," "I feel the hole where the ulcer was," etc.). However. even these reports were followed up with questions to ascertain the nature of the similarity in pain; if only the quality or the location was reported to be the same, the phantom limb pain was not included as a somatosensory memory.

Subjects also were asked to rate the similarity in intensity of the pre-amputation and phantom pains but this information did not serve as a criterion for inclusion since the pain intensity of a somatosensory memory appears to be analogous to the strength or vividness of a cognitive memory (or recollection): cognitive memories tend to fade with time elapsed since the original event, yet they continue to represent that event.

In order to minimize demand characteristics associated with the interview procedure, subjects had been informed that the study was investigating non-painful and painful phantom limbs. Equal attention was paid to reports of pre-amputation pains which did not recur in the phantom limb as those which did. The investigator avoided asking leading questions and although subjects were encouraged to elaborate their responses they were not prompted. Inconsistencies which occasionally arose over the course of one or more interviews with a subject were followed up with further questions to clarify the nature of the similarity in pains.

Pain assessment and psychological measures

Subjects completed the following questionnaires and personality inventories.

McGill Comprehensive Pain Assessment Schedule (MCPAS). The MCPAS [64] provides comprehensive information about the patient, including biological, psychological and social data. The abridged version used in this study was modified for use with amputees.

Eysenck Personality Inventory (EPI). The EPI [27] provides 2 unidimensional orthogonal measures of personality, each conceptualized along a continuum. These dimensions are extraversion-in- 
troversion (EPI-E) and neuroticism-stability (EPIN). A lie scale (EPI-L) is included to screen out blatant attempts at falsification.

Wesley Rigidity Questionnaire (WRQ). The WRQ [99] measures psychological rigidity using a 50 item forced-choice questionnaire. Concurrent validity of the WRQ was established through its relationship with performance on the Wisconsin Card-Sorting Test.

Beck Depression Inventory (BDI). The present study used the 21 item BDI [5]. Each item is composed of several statements varying in the degree to which they reflect depressive symptoms and attitudes.

Spielberger Trait Anxiety Inventory (STAI-T). The STAI-T [89] measures dispositional anxiety as a stable personality trait and consists of 20 statements that pertain to how anxious the subjects "generally feel."

\section{Results}

\section{Frequency of somatosensory memories}

Forty-four of the 68 subjects (64.7\%) reported that they had experienced at least one type of pain in their limb at the time of the amputation. Twenty-nine subjects reported somatosensory memories which resembled painful or non-painful pre-amputation sensations. Twenty-one of the 29 reported SMps, 2 reported SMfs, 4 reported both SMps and SMfs, and 2 reported only SMs of non-painful pre-amputation experiences. Together, the 29 subjects experienced a total of 55 somatosensory memories. Three additional subjects reported having had SMps that had since disappeared. Thus, at the time of the interview, $42.6 \%(29 / 68)$ of the total sample reported at least one somatosensory memory (SMf or SMp) which resembled, in quality and location, a painful or non-painful pre-amputation sensation experienced before the limb was removed. Fifty-seven percent $(25 / 44)$ of those who reported having had preamputation pain at or near the time of amputation indicated that at least one of these pains continued to persist or recur in the phantom as SMps.

In addition, 21 subjects (all with PVD or PVD/DM) had a pre-amputation history of intermittent claudication characterized by severe leg pain brought on by walking: 11 subjects had only claudication pain; 10 also had other pains at or near the time of amputation and are included above. Only 1 of the 21 subjects with intermittent claudication claimed that he still suffered the same kind of pain referred to his phantom calf when he walked (with a prosthetic leg).

Sixteen subjects reported having had pain at or near the time of the amputation, but had never experienced these pains in the phantom limb. In

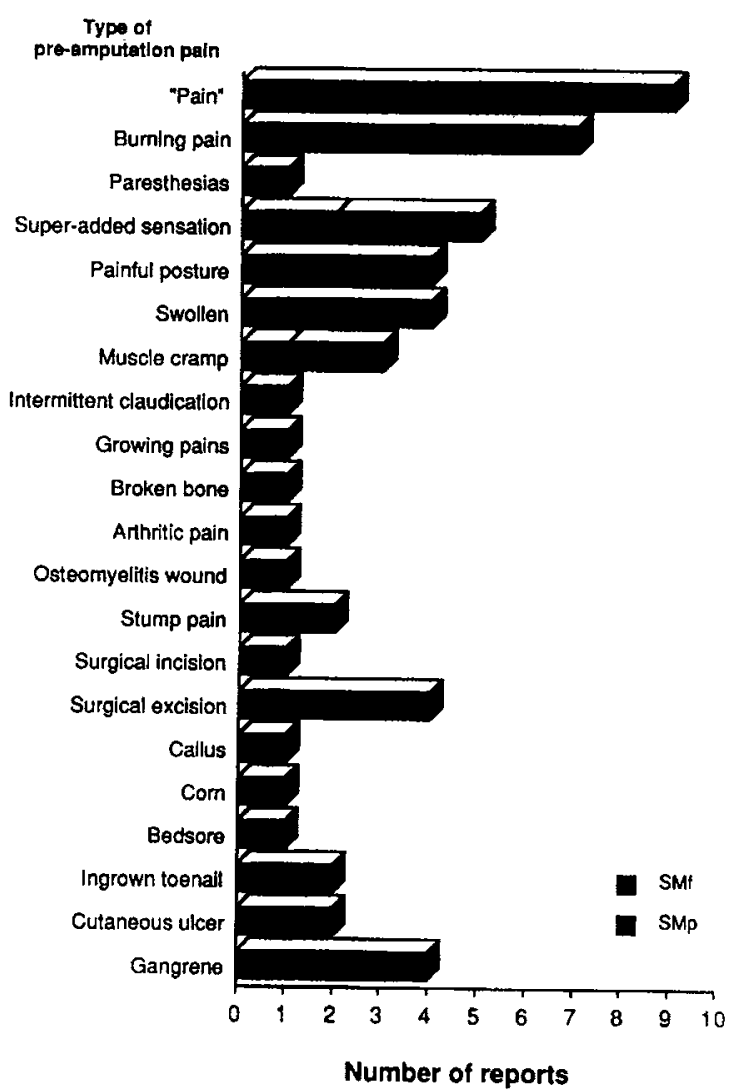

Fig. 1. Histogram showing the number of somatosensory memories (SMs) of various types of pre-amputation pain referred to the phantom limb after amputation. SMp refers to somatosensory memories of prior pains that were present at the time of amputation. SMf refers to somatosensory memories of former pains which were separated from the amputation by a pain-free interval (See Methods section for more details). All SMs are of painful pre-amputation sensations and/or lesions with the exception of the 5 somatosensory memories of superadded sensations and the single case of paresthesias which were all originally experienced before the amputation as non-. painful. 
addition, 4 subjects who reported SMps for some pre-amputation pains indicated that other pains which they had had at the time of amputation had never been represented in the phantom limb. Together these 20 subjects reported having had a total of 25 pre-amputation pains.

\section{Quality and location of somatosensory memories}

Fig. 1 shows the distribution of the 55 somatosensory memories according to the type or quality of pre-amputation experience. With the exception of the 5 reports of non-painful "super-added" sensations and 1 case of painless paresthesias, the somatosensory memories are predominantly replicas of distressing pre-amputation lesions and pains. The reports of SMps have been grouped into 10 categories and are displayed in Fig. 2. Also shown is the distribution of pre-amputation pains which were not experienced as somatosensory memories. Fig. 3 shows the distribution of SMps displayed according to the region or location of the limb in which the pains were reported.

Comparison of subjects with and without somatosensory memories

The sample was divided into 3 groups based on the presence or absence of phantom limb pain
(PLP). Group PLP/SM consisted of 25 subjects who reported phantom limb pain similar in quality and location to their pre-amputation pain ( $n=$ 23 with SMps and $\mathbf{n}=2$ with SMfs). Group PLP/No-SM consisted of 19 subjects who suffered from phantom limb pain but did not have pain prior to amputation $(n=13)$, or if they did $(n=6)$. it bore no resemblance to the subsequent phantom limb pain. Group No-PLP consisted of 17 subjects who did not suffer from phantom limb pain. Four subjects who reported non-painful somatosensory memories (of painful $(\mathrm{n}=2)$ and non-painful $(\mathrm{n}=$ 2) pre-amputation experiences) were excluded, as were the 3 subjects who reported having had SMps that had since disappeared.

Table II contains demographic and clinical characteristics of the 3 groups. They did not differ significantly in mean age $\left(F_{12,581}=1.33, P>0.05\right)$ or time since the amputation $\left(F_{(2.58)}=0.42, P>\right.$ $0.05)$. Furthermore, there were no significant diflerences with respect to gender $\left(\chi^{2}(2)=0.60, P>\right.$ $0.05)$, prosthetic use $\left(\chi^{2}(2)=3.41, P>0.05\right)$, level of amputation $\left(X^{2}(2)=1.61, P>0.05\right)$. number of limbs amputated $\left(\chi^{2}(2)=0.13, P>0.05\right)$, or whether the amputation followed an accident or illness $\left(\chi^{2}(2)=0.44 . \quad P>0.05\right)$. Finally, a comparison of the mean duration of pre-amputation

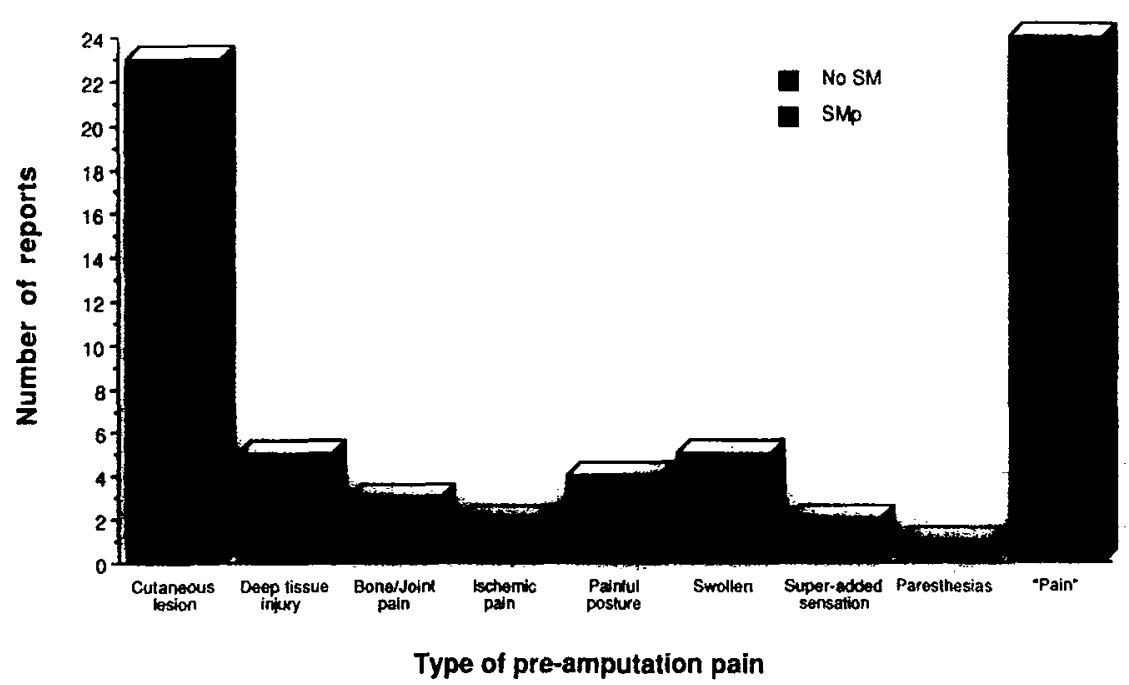

Fig. 2. Histogram showing the type and number of pains that were reported to have been present at the time of amputation and subsequently experienced in the phantom limb as somatosensory memories (SMp). Also shown are pains which were reported to have been present at the time of amputation but were not experienced as somatosensory memories (No SM). 


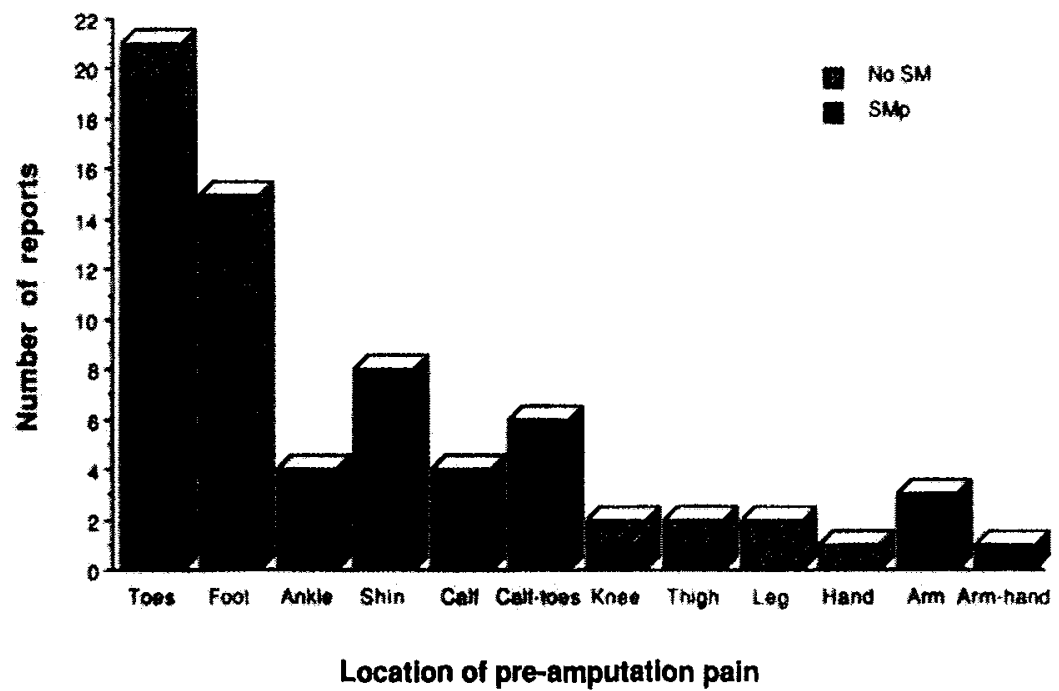

Fig. 3. Histogram showing the region of the limb that was reported to have been painful at the time of amputation and the number of pains that were subsequently experienced in the same region of the phantom limb as somatosensory memories (SMp). Also shown are regions of the limb in which pre-amputation pains were experienced, but not somatosensory memories (No SM).

\section{TABLE II}

A COMPARISON OF THE MEAN AGE, TIME SINCE AMPUTATION AND OTHER CLINICAL CHARACTERISTICS OF THE THREE GROUPS OF AMPUTEES

Standard deviations are provided in parentheses for the first two variables. Group PLP/SM: subjects with phantom limb pain similar in quality and location to their pre-amputation pain. Group PLP/No-SM: subjects who suffered from phantom limb pain but did not have pain prior to amputation, or if they did, it bore no resemblance to the subsequent phantom limb pain. Group No-PLP: subjects who did not suffer from phantom limb pain.

\begin{tabular}{|c|c|c|c|}
\hline \multirow{2}{*}{$\begin{array}{l}\text { Clinical } \\
\text { characteristics }\end{array}$} & \multicolumn{3}{|l|}{ Group } \\
\hline & $\begin{array}{l}\text { PLP/SM } \\
(n=25)\end{array}$ & $\begin{array}{l}\text { PLP/ } \\
\text { No-SM } \\
(n=19)\end{array}$ & $\begin{array}{l}\text { No-PLP } \\
(n=17)\end{array}$ \\
\hline $\begin{array}{l}\text { Age at interview } \\
\text { (years) }\end{array}$ & $56.4(14.5)$ & $62.7(14.0)$ & $57.9(8.6)$ \\
\hline $\begin{array}{l}\text { Years since ampu- } \\
\text { tation }\end{array}$ & $4.6(5.3)$ & $4.8(10.3)$ & $4.1 \quad(5.2)$ \\
\hline Number of males & $15(60 \%)$ & $13(68 \%)$ & $12(71 \%)$ \\
\hline $\begin{array}{l}\text { Uses prosthesis } \\
\text { regularly (n) }\end{array}$ & $12(48 \%)$ & $11 \quad(58 \%)$ & $13(76 \%)$ \\
\hline $\begin{array}{l}\text { Amputation } \\
\text { Above major } \\
\text { joint (n) }\end{array}$ & $(72 \%)$ & & $(53 \%)$ \\
\hline Due to illness (n) & $20 \quad(80 \%)$ & $14(74 \%)$ & $14(82 \%)$ \\
\hline Unilateral (n) & $20(80 \%)$ & $16(84 \%)$ & $14(82 \%)$ \\
\hline
\end{tabular}

pains that were later experienced as SMps $(2.8$ years, S.D. $=8.7$ years) with the duration of pains which did not occur in the phantom limb after amputation (1.1 years; S.D. $=3.0$ years) was not statistically significant $\left(F_{(1,60)}=0.86, P>0.05\right.$; based on log-transformed scores).

Table III shows the mean scores on the per-

\section{TABLE III}

A COMPARISON OF THE MEAN SCORES ON THE PERSONALITY, DEPRESSION, AND ANXIETY INVENTORIES FOR THE THREE GROUPS OF AMPUTEES

Standard deviations are provided in parentheses. Abbreviations as in Table II.

\begin{tabular}{lrlrr}
\hline Variable & \multicolumn{3}{l}{ Group } \\
\cline { 2 - 5 } & $\begin{array}{l}\text { PLP/SM } \\
\left(\mathrm{n}=24^{*}\right)\end{array}$ & $\begin{array}{l}\text { PLP/No-SM } \\
(\mathrm{n}=19)\end{array}$ & \multicolumn{1}{l}{$\begin{array}{l}\text { No-PLP } \\
(\mathrm{n}=17)\end{array}$} \\
\hline EPI-Extraversion & $13.2(4.0)$ & $11.2(3.6)$ & $11.1(4.0)$ \\
EPI-Neuroticism & $9.9(5.9)$ & $10.8(6.2)$ & $9.3(6.5)$ \\
EPI-Lie & $3.8(1.6)$ & $4.1(1.8)$ & $4.7(2.7)$ \\
WRQ-Rigidity & $26.0(5.4)$ & $29.1(7.6)$ & $29.4(5.7)$ \\
BDI-Depression & $9.8(10.2)$ & $11.2(7.7)$ & $8.5(7.1)$ \\
STAI-T-Anxiety & $35.8(12.6)$ & $36.9(10.4)$ & $38.1(12.0)$ \\
\hline
\end{tabular}

* $n=24$ instead of 25 due to one subject who could not read well enough to fill out the questionnaires. 
sonality, depression and anxiety inventories for the 3 groups. A series of univariate one-way ANOVAs comparing the 3 groups did not reveal any significant differences on the EPI-E, EPI-N, or EPI-L sub-scales $\left(F_{(2,57)}=2.25 . \quad P>0.05\right.$; $\left(F_{(2.57)}=0.29, P>0.05 ;\left(F_{(2.57)}=1.11, P>0.05\right.\right.$, respectively), the WRQ $\left(F_{(2,57)}=1.92, P>0.05\right)$, BDI $\left(F_{(2.57)}=0.42, P>0.05\right)$. or STAI-T $\left(F_{(2.57)}\right.$ $=0.19, P>05$ ).

"Super-added" sensations of non-painful pre-amputation experiences

Five subjects described phantom limb sensations that resembled non-painful sensations experienced in the intact limb before it was amputated. Two of them reported the experience of a shoe-clad phantom foot. A third subject reported feeling a sensation like that of the bandages which once wrapped his wound. The fourth subject was a 23-year-old young man who had lost his right leg from above the knee as the result of a motorcycle accident. He was interviewed approximately 2 months after the amputation. One sensation which he originally experienced at the accident scene occurred when the ambulance attendants arrived and were required to cut off his right boot in order to release his foot. He felt a sensation which he described as a considerable release of constrictive pressure when his foot was freed from the boot. This sensation has recurred several times since the amputation.

Another patient, presented in detail elsewhere [48] was re-interviewed 5 years later for the present study. In the earlier report, she had described a "draining" in her phantom hand and arm that resembled a pre-amputation sensation she had experienced on many occasions when the ulcers on her arm had been drained. During the present study she experienced the same sensation and described it as it was occurring:

"Now my hand seems to be starting to drain ... It's like draining it from edema. It's as though it were trickling out, and it's a little cooler ... It reminds me of how my hand and arm felt when I was in that machine at the hospital having the edema pumped out ... It's as though my arm were up and the fluid was leaving it ... there's the draining feeling leav- ing the fingertips, going down the fingers int the palm of the hand, through the palm into this part [the heel of the hand], then it just doesn't happen. ... The wrist is there, but it isn't part of the draining" (Transcribed verbatim from tape recording).

\section{Multi-modal somatosensory memories}

In 5 cases the SMps were described as more than just somatosensory in nature but were perceptually complex experiences that included descriptions of associated visual, tactile and motor components that had accompanied the original experience. Painful somatosensory memories involving multiple modalities frequently were accompanied by high levels of anxiety and stress.

One woman, reported above, had a visual image of her phantom foot "wearing a white sock and a black patent leather shoe with straps." Another subject continued to reach down to cup the wound which he felt on his phantom shin whenever the pain came on, just as he had done for years prior to the amputation. The third subject who had developed gangrene in his big toe prior to the amputation reported that when he feels the same burning in his phantom toes he also has a mental image of the big toe, discoloured and black, as it was prior to the amputation.

The fourth subject had undergone a right below-knee amputation for PVD. She reported having had an extremely painful ulcer in her big toe which was frequently cleaned and treated by her physician in an effort to avoid amputation. During the interview she gave the following description of the pain in her phantom toe: "It was the worst pain of my life. I'm feeling the hole is there and it's paining me! It feels like he [the physician] is cleaning out the hole and packing in medication and cotton."

The fifth subject was seen 15 months after a left above-knee amputation. He had spent 18 months in hospital following a motorcycle accident in which his left leg was severely damaged. He had had continuous pain in his leg ever since the day of the accident. He reported that during his hospital stay he had undergone numerous surgical operations on his leg, including one emergency procedure performed without an 
anesthetic. He described his reaction to this procedure as follows: "When he [the surgeon] opened it up, it burned so much, like taking a match and letting it burn ... and I fainted away." He had brought to the interview photographs of his leg, taken at the hospital, showing the wound ( 7 " long and 2 " wide) on his shin that he continued to experience in the phantom limb. He stated that he is frequently awakened at night feeling weak, covered in sweat, and in a state of panic. He feels the wound and an excruciating pain in the phantom limb that is the same as the pain he had suffered before the amputation. At those moments, the painful phantom feels as if "the doctors and nurses are there working on it."

\section{Eliciting stimuli}

With few exceptions, these subjects were unable to specify the eliciting stimuli or conditions that gave rise to the perception of somatosensory memories. Five subjects noticed a relationship between the onset of the somatosensory memory and certain behaviors or environmental events. Two of them reported that changes in the weather would still bring on the same pain they used to feel prior to the amputation when their limbs were intact. One felt an increase in the tight, vice-like pain around her phantom ankle. The other claimed that she was still capable of predicting when the weather was about to change by the onset of an arthritic ache in her phantom knee. The third, with a right below-knee amputation, discovered that if he lay on his back and maximally flexed his right knee, he could briefly elicit the sensation of "the dry, callused, tight skin" that he used to feel on the sole of his foot. If he continued to flex and extend his knee for a minute or so, he found that the sensation persisted until he stopped.

A fourth subject reported that for about 1 year after the amputation he felt the pain and the "hole" from a gangrenous pre-amputation ulcer on the medial aspect of his foot that had been "bigger than a silver dollar." At the time of the interview he could reproduce the sensation of the ulcer at will by concentrating on his phantom limb, but unless he did so the somatosensory memory remained out of his awareness. The fifth subject continued to experience the pain of inter- mittent claudication in his phantom calf after walking a short distance.

\section{Discussion}

Pain experienced in a limb at the time of, or shortly before, amputation frequently persists in the form of a somatosensory memory referred to the phantom limb. In the above study, $57 \%$ of subjects who reported to have had pain at or near the time of amputation claimed that the phantom limb pain they experienced resembled the preamputation pain in quality and location. This figure compares well with the results of other studies $[1,14,48,71]$. The slightly lower prevalence reported by Browder and Gallagher [14] and Parkes [71] can be explained by their inclusion only of patients who had fairly intense pre-amputation or phantom pains. In the present study, all instances of phantom limb pain that were reported to resemble the pain before amputation were recorded regardless of intensity.

Four studies $[45,80,82,97]$ report rates of somatosensory memories which are considerably lower. Roth and Sugarbaker [80] and Sherman et al. [82] provide few details about the type of pre-amputation pain experienced, making comparison of these studies difficult. Wall et al. [97] found that only $12.5 \%$ of their patients reported the location of their pain to be identical before and after amputation. The major difference between their study and most others, including the present one, is that their patients had amputations because of neoplastic disease and not occlusive vascular disease or trauma.

The results of the study carried out by Jensen et al. [45] deserve serious consideration since the design was prospective and patients were followed over a 2 year period. However, since they give few details about (a) their procedure of pain assessment before and after amputation, and (b) the types of pre-amputation pain experienced, it is difficult to account for the discrepancy between their results and those of the present study.

Nevertheless, there are several possibilities. First, we believe that the 2 studies examined different qualities of pain experience. Jensen et al. [45] used a limited number of limb locations and 
descriptors which tap only certain aspects of the sensory quality of the pain, but they did not ask the patients to describe their pain experience. That is. they did not set out to obtain precise. vivid descriptions of the pain experience prior to or after amputation and at no time did they report the nature of the pains or lesions the descriptors represented (e.g., an ingrown toe-nail, cutaneous ulcer. bypass incision, etc.). If any of their patients had experience of a wood sliver under a phantom fingernail [4] or a painful corn on the dorsal surface of the small toe [73]. it would not have been possible for them to express these experiences as a result of the narrow constraints of the procedures. In addition, most clinical pains show fluctuations in quality over time. yet they still represent the "same" pain to the person who experiences it. It is questionable whether the criteria used by Jensen et al. to determine similarity of location and quality would have been sensitive to this property of pain.

Second, the diagnosis of occlusive arterial disease in $88 \%$ of patients [45] and the description of "intermittent limb pain" suggests that a large number of their patients suffered the pain of intermittent claudication. The results of the present study showed that this pain occurs very infrequently as a somatosensory memory after amputation with only 1 of 21 subjects reporting it. Thus, their inclusion of a pain which occurs very frequently prior to amputation but rarely as a phantom pain, may in part have led to a lower estimate of the percentage of amputees reporting similar pains before and after amputation.

Third, the definition of "pre-amputation pain" used in the study by Jensen et al. [45] encompassed a wider time frame than that of the present study. Although 98\% (57) of Jensen's patients had suffered pain in the limb within 6 months of amputation, 29\% (17) were free of pain the day before amputation [44,45]. Nevertheless, on the day before amputation, these 17 patients were required to rate the quality and location of the pain as they remembered it (Jensen, personal communication). The incidence of similar pains before and after amputation is not presented separately for these 17 patients, but the literature summarized in Table I shows that reports of painful
SMfs are rare compared to SMps. This relative rarity is also supported by the results of the present study. Thus, the incidence of similarity may have been reduced by the 17 patients who were not in pain the day before amputation.

Finally. many patients who undergo amputation have several types of pre-amputation pain (e.g., pain from cutaneous ulcers. surgical bypass incisions, gangrene. intermittent claudication). Unless a description of each is obtained prior to amputation. it is possible that a somatosensory memory which develops is not one of those previously rated. Furthermore, given that somatosensory memories tend to be transient and of relatively short duration. it is possible that some patients will not be experiencing them at the time of interview. These considerations may, in part. help to explain the discrepancy between the results of the present study and that of Jensen et al. [45].

\section{Considerations of a retrospective study}

The lack of an objective description of the pre-amputation pain, to which the subsequent phantom limb pain could be compared, raises the valid criticism that the patients' cognitive memory of pain may not accurately reflect the original pain experience. Several studies have addressed the issue of the accuracy and reliability with which a variety of past pains are remembered $[24,39,49$. $51.56 .57 .79]$. On the whole, the results indicate that patients are surprisingly good at remembering past pains, and that when distortions occur. they involve mainly the intensity of the remembered pains $[24.56,57]$. Severe pains tend to be overestimated and remembered as worse; mild or moderate pains are underestimated [51.79]. Memory for the qualitative sensory dimension of pain. assessed with verbal descriptors instead of numerical values or visual analog scales, appears to be less vulnerable to distortion $[39,56,79]$.

These results suggest that the subjects in the present study were minimally affected by the distorting effects of memory or time since the focus was on the somatosensory qualities of their phantom limb pain - the very dimension which appears to be least affected in studies of pain and memory $[39,56,79]$. Intensity, which is most 
vulnerable to distortion $[24,56,57]$, was not used as a criterion for inclusion. In addition, the patients who were experiencing somatosensory memory pains at the time of the interview were not recalling how a pain felt in its absence, but recognizing one that persisted (i.e., identifying a current sensory experience as familiar). It is well established that recognition produces more accurate results than recall in standard tests of memory [31].

Nevertheless, the possibility remains that in seeking a rational explanation for their phantom pain, some subjects may have concluded that it resembled a past pain when no relationship existed, thus yielding an inflated estimate of the true percentage of amputees with somatosensory pain memories. A well-controlled prospective study is needed before a definitive statement can be made concerning the incidence of somatosensory memories and the nature of the similarities between pre-amputation pain and phantom limb pain. With these caveats in mind, the remainder of the discussion deals with several factors which may be important in the formation and subsequent activation of somatosensory memories.

Factors which could influence the development of somatosensory memories

Pre-amputation pain. Pain, or possibly stress, appears to be crucial for the development of somatosensory memories since all but a few of the original pre-amputation sensations were painful. The importance of pain in establishing this type of phantom phenomenon was also noted by Nathan $[68,69]$. The occasional case report can be found in which non-painful sensations subsequently recur as phantom phenomena following amputation or spinal anesthesia, but these are exceptions (see Table I). In general, the development and expression of somatosensory memories are intimately tied to the experience of pain. But the aspects of pain which are crucial to this relationship remain unknown.

Temporal relation between pain and amputation. When pain is experienced in a limb at or near the time of amputation there is a high probability that it will persist into the phantom limb and continue to cause the patient distress and suffering but this conclusion should be tempered by the retrospective approach of the present study. It appears that if there is a discontinuity or a pain-free interval between the experience of pain and amputation, the likelihood of that pain becoming incorporated into the phantom limb is reduced. The importance of the temporal contiguity of pain and amputation also seems to be supported by the preponderance of SMps over SMfs found in the clinical literature (Table I). It is also consistent with a study by Dennis and Melzack [22] who found that the distribution of autotomy latencies among rats that had received a formalin injection into the forepaw $1 \mathrm{~h}$ prior to dorsal rhizotomy was significantly shorter than uninjured controls, but if the injection was made 4 weeks prior to deafferentation the difference in autotomy onset was negligible.

Alternatively, it may be that SMps outnumber SMfs because pain which is discontinuous with amputation may not be remembered as well as pain which is present at the time of amputation. The relative rarity of SMfs may reflect forgetting (or inaccessibility) of the cognitive component of former pre-amputation pains. After amputation, patients may demonstrate poor (or no) recognition of the somatosensory qualities of former pains and better recognition of recent ones even though the somatosensory memory component may be active in both instances.

Duration of pre-amputation pain. The length of time a patient's limb was reported to have been painful before the amputation was not related to the persistence or recurrence of a pain after amputation. Jensen et al. $[44,45]$ found, at the 8 day and 6 month interviews, that phantom limb pain was more prevalent among amputees who had reported pre-amputation pain of long ( $>1$ month) as opposed to short ( $<1$ month) duration but this finding does not necessarily address the issue of the similarity of pain before and after amputation. Evidence from animal studies $[16,17]$ indicates that even a brief $(15-20 \mathrm{sec})$ thermal injury of the hindpaw skin prior to sciatic and saphenous nerve transections is sufficient to produce an enhancement of autotomy in rats compared to uninjured controls.

Type and location of pre-amputation experience. The data presented in Figs. 2 and 3 suggest that 
many types of pain or body regions have the potential to become represented as a phantom pain following amputation, including annoying ingrown toe-nails, painful diabetic and gangrenous foot ulcers. the throb of a broken toe. surgical wounds on the shin and thigh, calf cramps and remarkably, even stump pain from a previous amputation. There is an obvious bias involved in being able to recognize, after amputation, the type and location of a pre-amputation pain if that pain continues to be an ongoing source of distress in the phantom limb. Consequently, subjects with somatosensory memories would be expected to report having had more pre-amputation pain than subjects whose pains did not recur. Thus, the histogram in Fig. 2. showing that every deep tissue injury, bone and joint pain. and painful posture that was reported to have been present prior to amputation was also experienced after, may be an indication of this bias. However, it may also reflect observations by Wall and Woolf [96] that increases in the excitability of spinal cord cells which receive input from transected peripheral nerves last many times longer following activation of nociceptors in muscle as opposed to cutaneous tissue.

Intensity of pre-amputation pain. The data shown in Fig. 1 indicate that there is a trend for severe pains (e.g., gangrene, cutaneous ulcers, surgical wounds) to be represented with a greater frequency than mild pains (e.g., ingrown toe-nail, corn, callus). Although Jensen et al. [45] did not record pre-amputation pain intensity, they reached a similar conclusion based on patient narcotic requirements: severe pre-amputation pain resulted in persistent phantom pain more frequently than did the less severe pains. It is possible that the development of somatosensory memories depends on a mechanism whose threshold is sensitive to a combination of intensity and duration so that intense pains of short duration (e.g., gangrene) and longlasting mild ones or innocuous sensations (e.g., of a bandage or a wedding band) produce sufficient excitation to produce long-term central changes. This might explain why duration or intensity of pre-amputation pain alone fail to differentiate patients who develop somatosensory memories from those who do not. A prospective study examining pre-amputation pain intensity and duration mas shed some light on this issue.

Psychopathology and emotional disturbance. Subjects who reported that their pain was the same before and after amputation could not be differentiated on personality, depression and anxiety inventories from those who did not have phantom limb pain or who had phantom limb pain which bore no resemblance to their pre-amputation pain. Thus, at the time of the interview, there was no evidence to suggest that levels of psychopathology and emotional disturbance were different for subjects who reported phantom limb pain of any type compared to pain-free subjects.

Input from modalities other than somesthesis. In several cases the somatosensory memories consisted of highly complex, perceptually-integrated phenomena including associated visual, tactile and motor components which had accompanied the original experience. Many of the pre-amputation pains had had corresponding visual elements such as a discoloured and festering diabetic ulcer, or a raw, red, open surgical wound. Some even had associated olfactory cues including the foul smell of putrid diabetic ulcers and gangrene. Such multi-modal input reported by subjects in the present study, and similar findings in the literature $[38.42,43,71,72.74 .88]$, suggest that activation of a pain memory after amputation may be facilitated by the integration of multi-modal inputs established prior to amputation.

Some subjects were exposed to a single, intensely painful and traumatic injury such as a motorcycle accident or an emergency surgical procedure performed without anesthetic. These brief. discrete events seemed to form the basis of vivid "flashbulb memories" [90] which accompanied the somatosensory pain memories after amputation. The high levels of anxiety which were experienced along with these phantom limb pains are suggestive of a post-traumatic chronic pain syndrome [65].

\section{A tentative hypothesis}

Based on the results of the present study and similar reports in the literature, it is possible to 
provide a general, speculative account of how a painful pre-amputation lesion becomes centrally represented and subsequently re-experienced in the phantom limb following amputation. It is proposed that a neural representation of the sensory qualities of the pre-amputation pain is formed and strengthened during single or multiple occurrences of the pain experience. This representation presumably encodes the particular spatial and temporal pattern of nerve impulses produced by the intensity, quality and body location of the lesion. Its development is hypothesized to depend on a mechanism which is sensitive both to the intensity and the temporal characteristics of the lesion so that brief but intense pains as well as mild ones of long duration are established when a critical threshold is exceeded. Once this higher-order somatosensory memory component has been formed, it can be activated even when only some of its elements are present in the sensory input $[7,61]$. The loss of normal afferent input following amputation may release the tonic inhibition governing a previously established somatosensory representation or allow an existing one to persist unchecked.

The affective or emotional tone that accompanies the experience of a pain memory appears not to be a re-activation of a stored representation, but is thought to be generated on a moment-bymoment basis. Thus, the patient's affective response is modulated as a joint function of the intensity, quality and location (in the phantom limb) of the somatosensory component, the personal meaning of the pain, and other cognitiveevaluative factors which determine any pain experience. Together these events give rise to the unified experience of a familiar pre-amputation pain which is referred to the phantom limb with all the qualities of the past pain.

\section{Conclusions and implications}

The results of the present study suggest that the somatosensory memories described here are not merely images or cognitive recollections (although obviously a cognitive component is involved); they are direct experiences of pain (and other sensa- tions) that resemble an earlier pain in location and quality. The precise details of the experiences of pain described by the patients involve localization, discrimination, affect and evaluation-that is, all the dimensions of perceptual experience-and these properties are a function of integrated brain activity. It is likely that the outputs of sensitized spinal cells activate the neural cell assemblies in the brain that subserve memories of earlier events. Somehow the memory trace is activated to produce the nerve impulse patterns that give rise to perceptual experience.

The separate somatosensory and cognitive components that appear to underlie the unified experience of a pain memory are consistent with recent evidence of multiple, dissociable memory systems [90] which specialize in processing specific kinds of information. Further advances in knowledge about the neural mechanisms of memory may reveal the substrates of the remarkable somatosensory memories described by patients in the literature review and study presented above. A well-controlled prospective study of the similarities between pre-amputation pain and phantom limb pain may help to determine the extent to which the precise descriptions of pain quality, location and intensity are a faithful reflection of events in the somatosensory system or represent a cognitive-evaluative process imposed upon a less distinct somatosensory signal.

Two implications for treatment are suggested by the present study. First is the obvious strategy of keeping patients free of pain as long as possible prior to the amputation in order to prevent the formation of a somatosensory memory [3]. Second, the results indicate that: (1) even pre-amputation pains of very short duration were reported to persist after amputation, and (2) the vast majority of somatosensory memories were of pains which were present at, or very near, the time of amputation. These 2 considerations raise the possibility that the injury barrage produced during amputation may also produce lasting changes which are later experienced as phantom limb pain. Use of combined general and spinal anesthesia during amputation should be more effective than general anesthesia alone in reducing the incidence of post-operative phantom limb pain arising from the 
cutting of nerves. tissue and bone since the additional spinal block would interfere with the formation of somatosensory memories by blocking nociceptive impulses at the level of the spinal cord. Amputation performed under general anesthesia alone would not prevent formation of the somatosensory memory component since its formation is independent of the conscious awareness of pain $[40,69,77]$. This suggestion is supported by recent work [33.59.95] but further evidence is needed to establish it beyond doubt.

\section{Acknowledgements}

We would like to thank the staff and patients of the following hospitals and institutions for their kind and helpful cooperation: Centre Hospitalier Catherine Booth, Fédération des Personnes Amputée du Québec, J.E. Hanger Inc., Montreal Convalescent Hospital Center, Montreal General Hospital, Orthomedics Inc., Royal Victoria Hospital, Ste. Anne's Veterans Hospital. We also thank Dr. Terence Coderre and Dr. Peter W. Nathan for their helpful suggestions and constructive comments on earlier drafts of the manuscript.

This paper was supported in part by postgraduate scholarships from the Medical Research Council of Canada and the Fonds FCAC pour l'Aide et le Soutien à la Recherche (Quebec Government) to Joel Katz, and by Grant A7891 from the National Sciences and Engineering Research Council of Canada to Ronald Melzack. This paper is derived, in part, from the first author's Ph.D. dissertation.

\section{References}

1 Appenzeller. O. and Bicknell, J.M., Effects of nervous system lesions on phantom experience in amputees. Neurology. 19 (1969) 141-146.

2 Arcadi. J.A., 'Phantom bladder': is this an unusual entity? (Letter to the Editor), J. Urol., 118 (1977) 354.

3 Bach, S., Noreng, M.F. and Tjéllden, N.U., Phantom limb pain in amputees during the first 12 months following limb amputation, after preoperative lumbar epidural blockade, Pain, 33 (1988) 297-301.

4 Bailey. A.A. and Moersch, F.P., Phantom limb, Can. Med. Assoc. J., 45 (1941) 37-42.
- Beck, A.T.. Ward, C.H. Mendelsom, M.. Moch. I. and trbough. 1. An inventory metsuring depressiom. Areh (ien. Psychiatry. 4 (1961) 561571

6 Berger. M. and Corstentrand. F.. Phantom illusions an spinal cord lesions. In: J. Siegfried and M. Zimmermanm (Fds.). Phantom and Stump Pain. Springer, Berlin, 1981. Pp. 66. 73 .

7 Bindra. D., A Theory of Intelligent Behavior. Wiley. New York. 1976.

8 Blood. A.M.. Psychotherapy of phantom limb pain in two patients. Psychiatr, Q., 30 (1956) 114-122.

9 Bornstein. B., Sur le phénomène du membre fantôme. Fncéphale (Paris), 38 (1949) 32-46.

10 Bors. F.. Phantom limbs of patients with spinal cord injury. Arch. Neurol. Psychiatry. 66 (1951) 610 -631.

11 Bradley, K.C.. The Sequelate of Amputation. Trustees of the Services Canteens Trust Fund, Australia, 1955.

12 Brena, S.F. and Sammons, E.E.. Phantom urinary bladder pain-Case report, Pain, 7 (1979) 197-201.

13 Bressler, B. Cohen, S.I. and Magnussen. F.. Bilateral hreast phantom and breast phantom pain. 1. Nerv. Ment. Dis.. 122 (1955) 315-320.

14 Browder. J. and Gallagher. I.P.. Dorsal cordotomy for painful phantom limbs. Ann. Surg.. 128 (1948) 456-469.

15 ("harcot. J.M., Leçons du Mardi à la Salpêtière. Vol. 1. (2nd ed.). Publications du Progrès Méd., Paris. 1892. pp. $344-355$.

16 Coderre. T.J. and Melzack, R.. Increased pain sensitivity following heat injury involves a central mechanism, Behav. Brain Res., 15 (1985) 259.262.

17 Coderre, T.J. and Melzack, R.. Procedures which increase: acule pain sensitivity also increase autotomy. Exp. Neurol.. 92 (1986) 713-722.

18 ('onomy, J.P.. Disorders of body image after spinal cord injury. Neurology. 23 (1973) 842-850.

19 Critchley. M.. The body-image in neurology. Lancet. 258 (1950) $335-341$.

20 Cronholm. B.. Phantom limbs in amputees, Acta Psychiatr. Neurol. Scand., Suppl. 72 (1951) 1-310.

21 Danke. F., Phantom sensations after amputation: the importance of localization and prognosis. In: J. Siegfried and M. Zimmermann (Eds.), Phantom and Stump Pain. Springer, Berlin, 1981, pp. 56-61.

22 Dennis, S.G. and Melzack, R., Self-mutilation after dorsal rhizotomy in rats: effects of prior pain and pattern of root lesions, Exp. Neurol.. 65 (1979) 412-421.

23 Dorpat. T.L.. Phantom sensations of internal organs, ('ompr. Psychiatry, $12(1971) 27$ - 35.

24 Fich. F.. Reeves, J.L.., Jaeger, B. and Graff-Radford, S.B.. Memory for pain: relation between past and present pain intensity, Pain, 23 (1985) 375-.379.

25 Engel. G.L.. 'Psychogenic" pain and the pain-prone patient, Am. J. Med., 26 (1959) 899-918.

26 Ettlin. T.M., Seiler, W. and Kaeser, H.E.. Phantom and amputation illusions in paraplegic patients. Eur. Neurol.. $19(1980) 12-19$.

27 Eysenck, H.L. and Eysenck, S.B.G., Manual for the 
Eysenck Personality Inventory, Educational and Industrial Testing Service, San Diego, CA, 1968.

28 Farley, D. and Smith, I., Phantom rectum after complete rectal excision, Br. J. Surg., 55 (1968) 40.

29 Frederiks, J.A.M., Occurrence of phantom limb phenomena following amputation of body parts and following lesions of the central and peripheral nervous system, Psychiatry Neurol. Neurochir., 66 (1963) 73-97.

30 Friedmann, L.W., The Psychological Rehabilitation of the Amputee, Thomas, Springfield, IL, 1978.

31 Glass, A.L. and Holyoak, K.J., Cognition, Random House, New York, 1986.

32 Gloyne, H.F., Psychosomatic aspects of pain, Psychoanal. Rev., 41 (1954) 135-159.

33 González-Darder, J.M., Barberá, J. and Abellán, M.J., Effects of prior anaesthesia on autotomy following sciatic transections in rats, Pain, 24 (1986) 87-91.

34 Guttman, L., Spinal Cord Injuries: Comprehensive Management and Research, Oxford, Blackwell, Oxford, 1973.

35 Haber, W.B., Observations on phantom-limb phenomena, Arch. Neurol. Psychiatry, 75 (1956) 624-636.

36 Haber, W.B., Reactions to loss of limb: physiological and psychological aspects, Ann. NY Acad. Sci., 74 (1958) 14-24.

37 Hécaen, H., David, M. and Talairach, J., Membres fantômes par compression de la queue de cheval; disparition après liberation des racines, Rev. Neurol., 77, (1945) 146-147.

38 Henderson, W.R. and Smyth, G.E., Phantom limbs, J. Neurol. Neurosurg. Psychiatry, 2 (1948) 88-112.

39 Hunter, M., Philips, C. and Rachman, S., Memory for pain, Pain, 6 (1979) 35-46.

40 Hutchins, H.C. and Reynolds, O.E., Experimental investigation of the referred pain of aerodontalgia, J. Dent. Res., 26 (1947) 3-8.

41 Jackson, H.J., On the comparative study of diseases of the nervous system, Br. Med. J., 2 (1889) 355-362.

42 Jacome, D., Phantom itching relieved by scratching phantom feet (Letter to the Editor), J. Am. Med. Assoc., 240 (1978) 2432.

43 James, W., The consciousness of lost limbs, Proc. Am. Soc. Psych. Res., 1 (1887) 249-258.

44 Jensen, T.S., Krebs, B., Nielsen, J. and Rasmussen, P., Phantom limb, phantom pain and stump pain in amputees during the first 6 months following limb amputation, Pain, 17 (1983) 243-256.

45 Jensen, T.S., Krebs, B., Nielsen, J. and Rasmussen, P., Immediate and long-term phantom pain in amputees: incidence, clinical characteristics and relationship to preamputation pain, Pain, 21 (1985) 267-278.

46 Jensen, T.S. and Rasmussen, P., Phantom pain and related phenomena after amputation. In: P.D. Wall and R. Melzack (Eds.), Textbook of Pain (2nd ed.), Churchill Livingstone, Edinburgh, 1989, pp. 508-521.

47 Kane, F.J. and Simes, L., Phantom urinary phenomena in hemodialysis patients, Psychosomatics, 18 (1977) 13-20.
48 Katz, J. and Melzack, R., Referred sensations in chronic pain patients, Pain, 28 (1987) 51-59.

49 Kent, G., Memory for pain, Pain, 21 (1985) 187-194.

50 Kogerer, H., On the psychology of the phantom limb, Z. Gesamte Neurol. Psychiatrie, 126 (1930) 381-383.

51 Kwilosz, D.M. and Gracely, R.H., Memory for post-surgical dental pain, Pain, Suppl. 2 (1984) S426.

52 Lhermitte, J. and Susic, Z., Pathologie de l'image de soi -les hallucinations des amputés: étude clinique et pathogénique, Presse Méd., 46 (1938) 627-631.

53 Leriche, R., The Surgery of Pain, Williams and Wilkins, Baltimore, MD, 1939.

54 Leriche, R., De la douleur comme objet de connaissance, Progr. Méd., 5 (1947) 115-129.

55 Leriche, R., A propos des algies des amputés, Mém. Acad. Chir., 73 (1947) 280-284.

56 Linton, S.J. and Götestam, K.G., A clinical comparison of two pain scales: correlation, remembering chronic pain. and a measure of compliance, Pain, 17 (1983) 57-65.

57 Linton, S.J. and Melin, L., The accuracy of remembering chronic pain, Pain, 13 (1982) 281-285.

58 Marbach, J.J., Phantom tooth pain, J. Endodont., 4 (1978) $362-372$.

59 McQuay, H.J., Carroll, D. and Moore, R.A., Post-operative orthopaedic pain - the effect of opiate premedication and local anaesthetic blocks, Pain, 33 (1988) 291-295.

60 Melzack, R., Phantom limb pain: Implications for treatment of pathologic pain, Anesthesiology, 35, (1971) 409_ 419.

61 Melzack, R., Phantom limbs, the self and the brain (The D.O. Hebb Memorial Lecture), Can. Psychol.. 30 (1989) 1-16.

62 Minski, L., Psychological reactions to injury. In: W.B. Doherty and D.D. Runes (Eds.), Rehabilitation of the War Injured, Philosophical Library, New York, 1943, pp. 115-122.

63 Mitchell, S.W., Injuries of Nerves and Their Consequences, Lippincott, Philadelphia, 1872.

64 Monks, R. and Taenzer, P., A comprehensive pain questionnaire. In: R. Melzack (Ed.), Pain Measurement and Assessment, Raven Press, New York, 1983, pp. 233240.

65 Muse, M., Stress-related, posttraumatic chronic pain syndrome: criteria for diagnosis, and preliminary report on prevalence, Pain, 23 (1985) 295-300.

66 Nashold, B.S. and Ostdahl, R.H., Dorsal root entry zone lesions for pain relief, J. Neurosurg., 51 (1979) 59-69.

67 Nathan, P.W., Reference of sensation at the spinal level, J. Neurol. Neurosurg. Psychiatry, 19 (1956) 88-100.

68 Nathan, P.W., Pain traces left in the central nervous system. In: C.A. Keele and R. Smith (Eds.), The Assessment of Pain in Man and Animals, Livingstone, Edinburgh, 1962, pp. 129-134.

69 Nathan, P.W., Pain and nociception in the clinical context, Phil. Trans. R. Soc. Lond., 308 (1985) 219-226.

70 Noordenbos, W. and Wall, P.D., Implications of the failure of nerve resection and graft to cure chronic pain produced 
by nerve lesions. J. Neurol. Neurosurg. Psychiatry. 44 (1981) 1068-1073.

71 Parkes, C.M. Factors determining the persistence of phantom pain in the amputee. J. Psychosom. Res.. 17 (1973) 97-108.

72 Parkes. C.M.. The psychological reaction to loss of a limb: the first year after amputation. In: I.G. Howells (Ed.). Modern Perspectives in the Psychiatric Aspects of Surgery. Brunner/Mazel. New York, 1976. pp. 515-532.

73 Pitres. A.. Etude sur les sensations illusoires des amputés, Ann. Médico-Psychol. (Paris), 55 (1897) 5-19: 177-192.

74 Price, D.B.. Miraculous restoration of lost body parts: relationship to the phantom limb phenomenon and to limb-burial superstitions and practices. In: W.D. Hand (Ed.). American Folk Medicine: A Symposium. University of California Press, Berkeley, 1976, pp. 49-71.

75 Reisner, H., Phantom tooth. In: J. Siegfried and M. Zimmermann (Eds.), Phantom and Stump Pain. Springer. Berlin, 1981. pp. $81-83$.

76 Reisner, H.. Phantom sensations (phantom arm) in plexus paralysis. In: J. Siegfried and $M$. Zimmermann (Eds.). Phantom and Stump Pain. Springer. Berlin. 1981. pp. $62-65$.

77 Reynolds, O.E. and Hutchins, H.C.. Reduction of central hyper-irritability following block anesthesia of peripheral nerve. Am. J. Physiol., 152 (1948) 658-662.

78 Riddoch. G., Phantom limbs and body shape. Brain. 64 (1941) 197-222.

79 Roche. P.A. and Gijsbers, K.. A comparison of memory for induced ischaemic pain and chronic rheumatoid pain. Pain. 25 (1986) 337-343.

80 Roth, Y.F. and Sugarbaker. P.H. Pain and sensations after amputation: character and clinical significance. Arch. Phys. Med. Rehabil., 61 (1980) 490.

81 Sherman. R.A.. Stump and phantom limb pain. Neurol. (lin. 7 (1989) 249-264.

82 Sherman, R.A.. Gall. N. and Gormly, J.. Treatment of phantom limb pain with muscular relaxation training to disrupt the pain-anxiety-tension cycle. Pain, 6 (1979) 47 55.

83 Sherman, R.A. and Sherman, C.I. A comparison of phantom sensations among amputees whose amputations were of civilian and military origins. Pain. 21 (1985) $91-97$.

84 Sherman, R.A., Sherman, C.J. and Parker. I... Chronic phantom and stump pain among American veterans: we sults of a study. Pain, 18 (1984) $83-95$.

85 Simmel. M.L.. On phantom limbs. Arch. Neurol. Psychidtry: 75 (1956) 6.37-647

86 Sliosberg. A.. I.es Algies des Amputés, Masson. Paris. 1948.

87 Solonen. K.A.. The phantom phenomenon in amputated Finnish war veterans. Acta Orthop. Scand., Suppl. 3. 54 (1962) 1-119.

88 Souques, M.M. and Poisch. Origine périphique des hallucinations des membres amputés. Rev. Neurol.. 13 (1905) $1112-1116$.

89 Spielberger. C.D., Gorsuch, R.L. and Lushene. R.E. STAl Manual for the State-Trait Anxiety Inventory, Consulting Psychologists Press Inc.. Palo Alto, CA, 1970.

90 Squire, L.R. Memory and Brain. Oxford University Press. ()xford. 1987.

91 Stevenson. G.H. Amputations with special reference to phantom limb sensations. Edinburgh Med. J.. 57 (1950) 44-56.

92 Szasz. T.S., Psychiatric aspects of vagotomy. IV. Phantom ulcer pain. Arch. Neurol. Psychiatry, 62 (1949) 728-733.

93 Van Bogaert. L.. Sur la pathologie de l'image de soi (Etudes anatomo-cliniques), Ann. Médico-Psychol. (Paris). 14 (1934) 519-555; 714-759.

94 Varma. S.K.. Lal, S.K. and Mukherjee, A.. A study of phantom experience in amputees, Ind. J. Med. Sci.. 26 (1972) 185-188.

95 Wall. P.D.. The prevention of postoperative pain. Pain, 33 (1988) 289-290.

96 Wall. P.D. and Woolf, C.J., Muscle but not cutaneous $($-afferent input produces prolonged increases in the excitability of the flexion reflex in the rat. J. Physiol. 356 (1984) 443-458.

97 Wall, R.. Novotny-Joseph, P. and Macnamara, T.E., Does preamputation pain influence phantom limb pain in cancer patients? South. Med. J.. 78 (1985) 34-36.

98 Wallgren, G.R., Phantom experience at spinal anaesthesia. Ann. Chir. Gynaecol. Fenniae. 43. Suppl. (1954) 486-500.

99 Wesley. E.L.. Perseverative behavior in a concept-formalion task as a function of manifest anxiety and rigidity. $J$. Abnorm. Soc. Psychol., 48 (1953) 129-134.

100 White. J.C. and Sweet. W.H. Pain and the Neurosurgeon. Thomas, Springfield, IL. 1969. 